\title{
Papers
}

\section{Prognostic evaluation of metallothionein expression in human colorectal neoplasms} Elli E Ioachim, Ann C Goussia, Niki J Agnantis, Melpomeni Machera,
Epameinondas V Tsianos, Angelos M Kappas
Metallothionein is a low molecular weight cysteine-rich protein, which has the ability to bind and sequestrate heavy metal ions such as zinc, copper, cadmium, and mercury. ${ }^{1}$ Synthesis of metallothionein is induced in various tissues by these metal ions as well as by endogenous factors such as glucocorticoids, interferon, interleukin-1, and vitamin $\mathrm{D}^{23}$ Metallothioneins have the ability to bind to large quantities of metal ions, thus causing an intracellular reservoir of sequestration function for essential or potentially toxic ions such as zinc and copper. Furthermore, metallothioneins play an important role in the detoxification of toxic metals, for example cadmium, ${ }^{4}$ and probably in the cellular protection against ionising radiation and alkylating agent cytotoxicity. ${ }^{156}$ Metallothionein overexpression has been found in various carcinoma cell lines resistant to certain anticancer drugs..$^{58}$ This protein may play a role in the development of drug resistance as well as in tissue resistance to metal carcinogens. Metallothionein also plays an important role in the homeostasis of zinc, a metal important to tumour growth and progression. ${ }^{9}$ Furthermore, metallothioneins are often associated with rapidly proliferating tissues, such as fetal and neonatal liver. ${ }^{10-12}$ There are mechanisms whereby metallothionein and p53 may interact in the control of cell division. ${ }^{13}$ In addition, in vitro studies have shown that exposure to a metal chelating agent induces a reversible conformation change in wild type p53 to the mutant form. It was thought that binding of zinc ions to cysteinyl residues stabilises the tertiary structure of p53. ${ }^{14}$ Some direct evidence indicates that certain tumour types have highly concentrated metallothionein. The mechanism of tumour metallothionein expression is not fully understood. There is evidence that metallothionein may play a role in various carcinogenic processes. Metallothionein expression seems to be significantly associated with progressive disease and with poor prognosis in invasive ductal carcinoma of the breast, ${ }^{15-19}$ malignant melanoma, ${ }^{20}$ and pancreatic carcinomas. ${ }^{21}$ In contrast, in colorectal carcinomas, metallothionein positivity is associated with a favourable clinical outcome, which may indicate variability of the biological significance
Keywords: metallothionein; cathepsin D; CD44, colorectal tumours 
Table 1 Antibodies used

\begin{tabular}{llll}
\hline Antibodies & Supplier & Dilution & Incubation time $^{*}$ \\
\hline Metalothionein, E9 & Dako & $1: 50$ & 1 hour \\
Cathepsin D (O13A) & Dako & $1: 300$ & 30 minutes $^{\star}$ \\
CD44 (Clone DF 1485) & Dako & $1: 40$ & Overnight $^{\star}$ \\
DO-7 (IgG2b)† & Ylem & $1: 200$ & Overnight $^{\star}$ \\
Anti-Rb (AB-5) $\dagger$ & Oncogene & $1: 80$ & Overnight $^{\star}$ \\
Anti-bcl-2(M0887)† & Dako & $1: 40$ & Overnight $^{\star}$ \\
C-erbB-2 (OM-11-925) & ICI, Cambridge & $1: 500$ & 1 hour \\
EGFR (AB-4) & Oncogene & $1: 500$ & 1 hour \\
PC-10 & Dako & $1: 50$ & 1 hour \\
Ki-67 & Dako & $1: 10$ & 30 minutes \\
\hline
\end{tabular}

^With microwave oven antigen retrieval.

†Citrate buffer incubation.

of metallothionein according to the tumour type. ${ }^{22}$ To elucidate the role of metallothionein in colorectal tumours we studied the immunohistochemical expression of metallothionein in conjunction with other potential prognostic variables such as cathepsin D, CD44, p53, Rb, bcl-2, c-erbB-2, epidermal growth factor receptor (EGFR), and proliferating activity estimated by the MIB- 1 and proliferating cell nuclear antigen (PCNA). We also assessed the conventional clinicopathological indices (age, sex, tumour size, tumour grade, and Duke's stage).

\section{Methods}

Tissue from surgical specimens resected from 94 patients with primary colorectal carcinoma and from 23 patients with colorectal adenomas was collected and processed by standard techniques to paraffin wax embedding, after fixation in neutral buffered formal saline for 24-28 hours. In 53 cases one additional sample was taken shortly after surgical removal and snap frozen in isopentane liquid nitrogen, using an embedding medium for frozen tissue specimens, OCT compound (Tissue Tek-Miles). The frozen specimens were stored at $-80^{\circ} \mathrm{C}$ until processing. Consecutive $4 \mu \mathrm{m}$ sections were stained with haematoxylin and eosin for histological diagnosis. Slides from all tumours were reviewed and divided according to WHO classification with regard of the grade of dysplasia; there were 13 adenomas with low

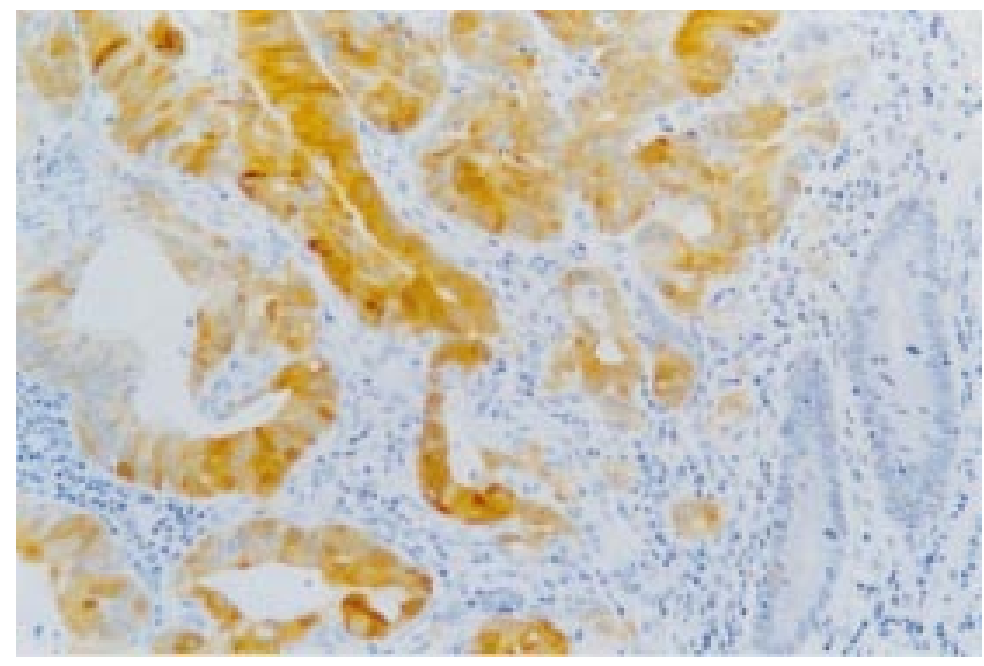

Figure 1 Strong metallothionein expression in a case of colorectal cancer. The reactivity is confined to the nuclei and the cytoplasm of the majority of neoplastic cells. Note the low metallothionein nuclear expression in the "normal" adjacent mucosa at the right. (Avidin-biotin-peroxidase complex stain, $\times 138$.) dysplasia and 10 with high dysplasia. Histologically, all colorectal carcinomas were adenocarcinomas. The age of patients at the time of surgery ranged from 26 to 86 years. According to WHO criteria, the grade of differentiation was high in 21 cases, moderate in 65, and low in seven. According to Dukes' stage there were 12 cases of stage A, 42 cases of stage B, and 40 cases of stage $\mathrm{C}$ disease. In most cases the adjacent normal mucosa was also examined.

\section{IMMUNOHISTOCHEMISTRY}

Immunohistochemistry on one or two selected blocks from each case was performed on $4 \mu \mathrm{m}$ tissue sections using the avidin-biotin and immunoperoxidase method as previously described. ${ }^{23}$ To unmask the epitopes of bcl-2, $\mathrm{p} 53$, and $\mathrm{Rb}$, we used treatment with microwaves and the sections were placed in $10 \mathrm{mM}$ citrate buffer, $\mathrm{pH}$ 6.0. Metallothionein, cathepsin D, CD44, c-erbB-2, EGFR, and PCNA staining was achieved without using the heat mediated antigen retrieval method. Subsequently, the sections were treated with $0.3 \%$ hydrogen peroxide $\left(\mathrm{H}_{2} \mathrm{O}_{2}\right.$ in methanol) for 30 minutes to block endogenous peroxidase. The sources and dilution of the antibodies are shown in table 1 . Tumour sections subjected to the whole procedure except for incubation with the primary antibody were used as substitute "negative" controls. For Ki-67 staining cryostat sections $4 \mu \mathrm{m}$ thick were air dried and fixed in absolute acetone. They were stained with monoclonal antibodies against $\mathrm{Ki}-67$ (Dako) using a sensitive two step indirect immunoperoxidase technique.

\section{Immunohistochemical evaluation}

Immunostaining (nuclear, cytoplasmic, or membrane cytoplasmic) was calculated as the percentage of positive tumour cells in relation to the total cell number in representative fields. Every stained nucleus was considered positive, irrespective of intensity. Only intense membrane immunostaining was considered to represent the overexpression of c-erbB-2 protein, as it has been shown to yield the best prognostic associations. $^{24}$

\section{STATISTICAL ANALYSIS}

The association of continuous variables was confirmed using a non-parametric test for two or several independent samples, or the Spearman bivariable correlation. Probability (p) values under 0.05 were considered statistically significant.

\section{Results}

The immunohistochemical localisation of metallothionein was both cytoplasmic and nuclear in the carcinoma cells (fig 1). Normal colorectal epithelium adjacent to carcinoma was negative or showed strong to weak cytoplasmic positivity for metallothionein, and the staining was confined to the proliferative zone, that is the lower crypts. Some peripheral nerves and smooth muscle cells were also stained. In 25\% of carcinomas and $30 \%$ of adenomas, strong metallothionein expression was observed in the majority of tumour cells, while focal metal- 
Table 2 Expression of metallothionein in correlation with clinicopathologiacal features of colorectal cancer

\begin{tabular}{|c|c|c|c|c|}
\hline & \multicolumn{3}{|c|}{ Metallothionein expression } & \multirow[b]{2}{*}{$p$ Value } \\
\hline & $(-)$ & $<10 \%$ & $>10 \%$ & \\
\hline Age (years) & & & & NS \\
\hline$<50$ & 17 & 4 & 6 & \\
\hline$>50$ & 36 & 10 & 16 & \\
\hline Sex & & & & NS \\
\hline Female & 29 & 5 & 13 & \\
\hline Male & 25 & 9 & 10 & \\
\hline Tumour size $(\mathrm{cm})$ & & & & NS \\
\hline$<5$ & 25 & 3 & 12 & \\
\hline$>5$ & 29 & 8 & 8 & \\
\hline Grade & & & & NS \\
\hline G1 & 16 & 3 & 2 & \\
\hline $\mathrm{G} 2$ & 37 & 10 & 18 & \\
\hline G3 & 3 & - & 4 & \\
\hline Duke's stage & & & & NS \\
\hline A & 9 & 2 & 1 & \\
\hline B & 25 & 7 & 10 & \\
\hline $\mathrm{C}$ & 22 & 5 & 13 & \\
\hline
\end{tabular}

Table 3 Metallothionein expression in correlation with potential prognostic variables in colorectal cancer

\begin{tabular}{|c|c|c|c|c|}
\hline \multirow[b]{2}{*}{ Prognostic variable } & \multicolumn{3}{|c|}{ Metallothionein expression } & \multirow[b]{2}{*}{$p$ Value } \\
\hline & $(-)$ & $<5 \%$ & $>5 \%$ & \\
\hline Cathepsin D & & & & NS \\
\hline$<10$ & 18 & 2 & 6 & \\
\hline$>10$ & 26 & 11 & 15 & \\
\hline CD44 & & & & $\mathrm{p}=0.01$ \\
\hline$(-)$ & 2 & - & 6 & \\
\hline$<10$ & 4 & & & \\
\hline$>10$ & 48 & 14 & 18 & \\
\hline p53 & & & & NS \\
\hline$<5$ & 23 & 5 & 10 & \\
\hline$>5$ & 32 & 9 & 14 & \\
\hline $\mathrm{Rb}$ & & & & NS \\
\hline$<10$ & 25 & 5 & 7 & \\
\hline$>10$ & 31 & 9 & 16 & \\
\hline bcl-2 & & & & NS \\
\hline$<5$ & 44 & 9 & 19 & \\
\hline$>5$ & 9 & 5 & 2 & \\
\hline c-erbB-2 & & & & NS \\
\hline$<25$ & 27 & 2 & 7 & \\
\hline$>25$ & 5 & 1 & 4 & \\
\hline EGFR & & & & NS \\
\hline$<25$ & 47 & 11 & 18 & \\
\hline$>25$ & 9 & 3 & 6 & \\
\hline Ki-67 & & & & NS \\
\hline$<50$ & 15 & 1 & 2 & \\
\hline$>50$ & 11 & 1 & 7 & \\
\hline PCNA & & & & NS \\
\hline$<50$ & 8 & 6 & 3 & \\
\hline$>50$ & 46 & 8 & 19 & \\
\hline
\end{tabular}

EGFR, epidermal growth factor receptor; PCNA, proliferating cell nuclear antigen.

lothionein positivity occurred in $15 \%$ of the carcinomas and $9 \%$ of the adenomas; $60 \%$ of the carcinomas and $60.9 \%$ of the adenomas almost completely lacked metallothionein expression. Results of metallothionein expression with CD, collagen type IV, p53, pRb, bcl-2, c-erbB-2, EGFR proliferating indices, and the clinicopathological features are shown in tables 2 and $3^{3}$. Metallothionein expression did not correlate statistically with any of the variables examined except for CD44: carcinomas with a low metallothionein expression showed high CD44 expression $(p=0.01)$. There was no significant difference of metallothionein expression between adenocarcinomas and adenomas.

\section{Discussion}

The biological mechanisms underlying metallothionein overexpression in tumours are not currently understood. Although expression of this protein has been associated with poor prognosis in a variety of tumours, ${ }^{15-21}$ in colorectal carcinomas it was shown that low expression was related to metastatic spread with lymph node involvement at the time of operation. ${ }^{22}$ This suggested that there was variability in the biological significance of metallothionein according to tumour type. However, in that study metallothionein expression was not considered as an independent prognostic variable in analysing the survival data. Mulder et al have reported a significantly decrease metallothionein content (determined by radioimmunoassay) in both adenomas and carcinomas compared with normal colonic mucosa. ${ }^{25}$ In our current study, although there was a decreased metallothionein expression with higher Duke's stage, we found no significant association between metallothionein expression and tumour progression. Furthermore, the metallothionein expression in some cases in adjacent normal mucosa, in adenomas as well as in carcinomas, suggests that this is an early event in tumour progression. This is in line with the findings in breast cancer and melanomas. ${ }^{18-20}$ However, the mechanism of tumour metallothionein expression is not fully understood. Hainaut and Milner ${ }^{14}$ found the altered conformation of the tumour suppressor protein p53 on the exposure to a metal chelating agent, thus suggested that binding of zinc ions to cysteinyl residues stabilises the tertiary structure of $\mathrm{p} 53$. Metallothioneins also have a high affinity for zinc ions and thus could act as intracellular sequestrators of zinc. Thus cells containing metallothionein in sufficient quantity to reduce intranuclear zinc ion levels and thus induce functional inactivation of p53 would acquire growth advantages and thus be able to proliferate and accumulate mutational events.

It has been hypothesised that mutation induced metallothionein overexpression may interfere with the function of zinc finger DNA binding transcription factors ${ }^{26}$ involved in the controlling of the expression of a wide range of genes regulating cell proliferation and apoptosis, such as p53, and conferring a growth advantage on the mutated cells. It has been also shown that metallothionein specific antisense oligonucleotides cause growth arrest and induction of apoptosis in metallothionein overexpressing breast carcinoma cells. ${ }^{27}$

In our study, although metallothionein and p53 were observed in both benign and malignant lesions, no correlation was detected between them in either group. These results are in line with reports ${ }^{18}$ concerning duct in situ carcinoma of the breast, which indicate that metallothionein and p53 overexpression may arise from independent mechanisms in early breast neoplasia.

We also found no correlation with proliferation indices, antiapoptotic bcl-2 protein, or the other potential markers of prognosis. An interesting finding was the inverse correlation between metallothionein and CD44 expression, though CD44 expression has been shown to be associated with metastasis and poor prognosis in colorectal cancer. ${ }^{28-30}$ This finding 
supports that of a previous study in which decreased metallothionein expression in colorectal carcinomas was correlated with metastatic state. ${ }^{22}$ In our previous study we found that CD44 expression in colorectal carcinomas was positively correlated with tumour size, tumour and stromal cell cathepsin D expression, and $\mathrm{pRb}$ expression. We also found an inverse correlation between CD44 expression and the antiapoptotic protein bcl-2. Thus we assumed that CD44 expression may be involved in the process of invasion and metastasis, probably with the cooperation of cathepsin $\mathrm{D}$, and its expression could be an indicator of poor prognosis in colorectal adenocarcinomas. ${ }^{31}$ In addition, the inverse correlation between metallothionein and CD44 expression would support the view that in colorectal cancer the metallothionein expression is associated with a favourable outcome. ${ }^{22}$ This would tend to confirm the different biological role of metallothionein expression in colorectal cancer, possibly because in colorectal tissue there is considerable inflammatory infiltrate and this could induce metallothionein synthesis through interferon production by activated $\mathrm{T}$ lymphocytes. However, the biological mechanisms underlying metallothionein overexpression in tumours are not currently understood. In a recent study, it was shown in normal colorectal mucusa that metallothionein overexpression is a result of somatic mutation in cells showing no obvious morphological evidence of a neoplastic phenotype. ${ }^{32}$ Thus it is still not clear whether the metallothionein expression in colorectal tumours represents an addition marker of the biological behaviour or whether it is an incidental finding.

\section{CONCLUSIONS}

Our results confirm that metallothionein expression does not to indicate aggressive biological behaviour in colorectal adenocarcinomas compared with other types of carcinoma. The inverse correlation with CD44 could suggest that the decreased metallothionein expression may contribute to metastatic spread and lymph node involvemant. In addition, metallothionein expression does not seem to be an independent marker of prognosis in colorectal cancer.

Many thanks to Mrs Antigoni Christodoulou for her skilled technical assistance. We are also grateful to Dr P Kanavaros, University of Thessalia, for helpful discussions and critical reading of the manuscript.

1 Nath R, Kambadur R, Gulati S, et al. Molecular aspects, physiological functions, and clinical significance of metallothioneins. Crit Rev Food Sci Nutr 1988;27:41-85.

2 Hamer DH. Metalothionein. Annu Rev Biochem 1986;55: 913-51.

3 Slater ER, Cato ACB, Karin M, et al. Progesterone induction of metallothionein-IIA gene expression. $\mathrm{Mol}$ Endocrinol 1988;2:485-91.

4 Leber AP, Miya T. A mechanism for $\mathrm{Cd}$ and $\mathrm{Zn}$ induced torelance to cadmium toxicity: involvement of metallothionein. Toxicol Appl Pharmacol 1976;37:403-14.

5 Kelley SM, Basu A, Teicher BA, et al. Overexpression of metallothionein confers resistance to anticancer drugs. Science 1988;241:1813-15.
6 Thornally PJ, Vasak M. Possible role of metallothionein in protection against radiation-induced oxidative stress. Kiprotection against radiation-induced oxidative stress. Kinetics and mechanism of its reaction with superoxide an hydroxyl radicals. Biochim Biophys Acta 1985;827:36-44. 7 Andrews PA, Murphy MP, Howell SB. Metallothioneincells. Cancer Chemother Pharmacol 1987;19:149-54.

8 Webber MM, Rehman SMM, James GT. Metallothionein induction and deinduction in human prostatic carcinoma cells: relationship with resistance and sensitivity to adriamycin. Cancer Res 1988;48:4503-8.

9 Webb M, Cain K. Functions of metallothionein. Biochem Pharmacol 1982;31:137-42.

10 Riordan JR, Richard V. Human fetal liver contains both zinc and cooper-rich forms of metallothionein. 7 Biol Chem 1980;255:5380-4.

11 Ryden L, Deutsch HF. Preparation and properties of the major copper-binding component in human fetal liver. $\mathcal{f}$ Biol Chem 1978;253:519-24.

12 Banerjee D, Onosaka S, Cherian MG. Immunohistochemical localization of metallothionein in cell nucleus and cytoplasm of rat liver and kidney. Toxicol 1982;24:95-105.

13 Cherian MG, Huang PC, Klaassen CD, et al. National Cancer Institute workshop on the possible roles of metallothionein in carcinogenesis. Cancer Res 1993;53:922-5.

14 Hainaut P, Milner J. A structural role for metal ions in the "wild-type" conformation of the tumour suppressor protein p53. Cancer Res 1993;53:1739-42.

15 Fresno M, Wu W, Rodriguez JM, et al. Localisation of metallothionein in breast carcinomas. An immunohistochemical study. Virchows Arch [A] 1993;423:215-19.

16 Haerslev T, Jackobsen K, Nedergaard L, et al. Immunohistochemical detection of metallothionein in primary breast carcinomas and their axillary lymph node metastasis. Pathol Res Pract 1994;190:675-81.

17 Schmid KW, Ellis IO, Gee JMW, et al. Presence and possible significance of immunocytochemically demonstrable metallothionein over-expression in primary invasive ductal carcinoma of the breast. Virchows Arch [A] 1993;422:153-9.

18 Douglas-Jones AG, Schmid KD, Bier B, et al. Metallothionein expression in duct carcinoma in situ of the lothionein expression in duct carcino

19 Bier B, Douglas-Jones A, Totsch M, et al. Immunohistochemical demonstration of metallothionein in normal human breast tissue and benign and malignant breast lesions. Breast Cancer Res Treat 1994;30:213-21.

20 Zelger B, Hittmair A, Schir M, et al. Immunohistochemically demonstrated metallothionein expression in malignant melanoma. Histopathology 1993;23:257-64.

21 Ohshio $\mathrm{G}$, Imamura $\mathrm{T}$, Okada $\mathrm{N}$, et al. Immunohistochemical study of metallothionein in pancreatic carcinomas. F Cancer Res Clin Oncol 1996;122:351-5.

22 Ofner D, Maier $\mathrm{H}$, Riedmann $\mathrm{B}$, et al. Immunohistochemical metallothionein expression in colorectal adenocarcinoma: correlation with tumor stage and patient adenocarcinoma: correlation with tumo
survival. Virchows Arch 1994;425:491-7.

$23 \mathrm{Hsu}$ SM, Raine L, Fanger H. Use of avidin-biotinperoxidase complex (ABC) in mmunoperoxidase techniques: a comparison between $\mathrm{ABC}$ and unlabelled antibody (PAP) procedures. F Histochem Cytochem 1981;29: 577-80.

24 De Potter CR, Beghin C, Makar AP, et al. The neuoncogene protein as a predictive factor for haematogenous metastases in breast cancer patients. Int 7 Cancer 1990;45. 55-8.

25 Mulder TP, Verspaget HW, Janssens AR, et al. Neoplasiarelated changes of two copper $(\mathrm{Cu}) /$ zinc $(\mathrm{Zn})$ proteins in the human colon. Free Radic Biol Med 1990; 9:501-6.

26 Zeng J, Heuchel R, Schaffner W, et al. Thionein (apothionein) can modulate DNA binding and transcription actiation by zinc finger containing factor SP1. FEBS Lett 1991;179:310-12.

27 Abdel-Mageed AB, Agrawal KC. Anti-sense downregulation of metallothionein induces growth arrest and apoptosis in human breast carcinoma cells. Cancer Gene Ther 1996;3(suppl): 93 .

28 Jackson PA, Green MA, Pouli A, et al. Relation between stage, grade, proliferation, and expression of p53 and CD44 in adenomas and carcinomas of the colorectum. $\mathcal{f}$ Clin Pathol 1995;48:1098-101.

29 Tanabe KK, Ellis LM, Saya H. Expression of CD44 R1 adhesion molecule in colorectal carcinomas and metastases. Lancet 1993;341:725-6.

30 Wielange VJM, Heider K-H, Offerhaus GJA. Expression of CD44 variant proteins in human colorectal cancer is related to tumor progression. Cancer Res 1993;53:4754-6.

11 Ioachim E, Goussia A, Agnantis NJ. Glycoprotein CD44 expression in colorectal neoplasms. An immunohistochemical study including correlation with cathepsin D, extracellular matrix components, p53, Rb, c-erbB-2, EGFR and proliferation indices. Virchows Arch 1998;434: $45-50$.

32 Jasani $\mathrm{BH}$, Campbell F, Navabi $\mathrm{H}$, et al. Clonal overexpression of metallothionein is induced by somatic mutation in morphologically normal colonic mucosa. F Pathol 1998;184:144-7. 